\title{
EFECTOS DE LA CRISIS DE 2007 EN LAS FINANZAS PÚBLICAS DE MÉXICO
}

\section{THE EFFECT OF THE 2007 CRISIS ON MEXICO'S PUBLIC FINANCE}

\author{
Sergio Enrique Beltrán-Noriega1; Rubén Antonio González-Franco2 y Luis Alfredo \\ Ávila-López3
}

Candidato a Doctor en Estudios Fiscales, Profesor Investigador de Tiempo Completo de la Facultad de Contaduría y Administración de la Universidad Autónoma de Sinaloa1. Doctor en Estudios Fiscales, Profesor Investigador de Tiempo Completo2. Maestro en Economía Mundial, Southwestern University of Finance and Economics3.

\section{RESUMEN}

A finales del siglo pasado y principios de este, los efectos en la economía mundial han venido repercutiendo en la situación económica, política y financiera de varias naciones, teniendo un impacto significativo en las economías de América Latina, afectando entre otros aspectos el comercio, el flujo de capital, la inversión extranjera directa y las remesas. En este análisis se identifican $\mathrm{y}$ analizan los mecanismos macroeconómicos que causan los desequilibrios en las economías con énfasis en Latinoamérica, por medio de revisión bibliográfica de teorías económicas clásicas y modernas, y de la recolección de datos de instituciones especializadas. Los resultados empíricos arrojan que la economía obtiene estos resultados por algunos elementos como la estructura demográfica, el aspecto tributario, la dependencia de energéticos, su sector crediticio y publico, el impacto del sistema social en la cuenta corriente.

Palabras Claves: globalización, comercio internacional, empleo, corriente de capital, impuestos.

Recibido: 04 de diciembre de 2011. Aceptado: 02 de marzo de 2012. Publicado como ARTÍCULO CIENTÍFICO en Ra Ximhai 8(3): 311-329.

\section{SUMMARY}

At the end of the last century and beginning of this, the effects on the global economy have been impacting the economic, political and financial situation of several nations, having a significant impact on the economies of Latin America, and among other aspects affecting trade, capital flows, foreign direct investment and remittances. This analysis identifies and analyzes the mechanisms that cause macroeconomic imbalances in economies with emphasis on Latin America, through literature review of classic and modern economic theories, and data collection of specialized institutions. The empirical results shows that the economy gets these results by some factors such as demographic structure, the aspect of taxation, energy dependence, the credit and public sector, and the impact of social system in the current account.

Keywords: globalization, international trade, employment, capital flow, taxation.

\section{INTRODUCCIÓN}

En la economía internacional y nacional,

Vease, Held, D., A. McGrew, D. Goldblatt y J. Perraton (eds.), Global Tranasformation, Stanford University Press, 1999, pag.2. 
se han registrado intensos procesos de transición, caracterizados por eldesmesurado avance de la globalización. La intensidad de cambios tecnológicos y el resurgimiento de destacadas economías como los países de China, Brasil, India y otros, así como drásticas transformaciones en los intercambios comerciales y financieros, han conducido a que países en vías de desarrollo incursionen en segmentos dinámicos de la economía mundial.

No obstante a esta dinámica, la globalización per se, es un hecho muy complejo, desde el orden técnico económico, hasta el aspecto socio político y cultural. Es importante tener en cuenta que el motor de la globalización es el interés económico de las naciones, sin embargo, este fenómeno no debe reducirse sólo a este aspecto, dado que en este hecho se presentan por una parte ganadores y por otra, perdedores; asimismo, su desarrollo trastoca problemas ecológicos, que son provocados por la alta industrialización de organizaciones económicas de una magnitud transnacional pertenecientes en su mayoría a países desarrollados, afectando en ocasiones a naciones de economías emergentes y a los de vías en desarrollo.

En este contexto, Hallivis (2003), señaló que el fenómeno de la globalización hace que todos los países requieran de todos. Siendo cada vez más dificil pensar en autarquías, dada la interrelación prevaleciente entre las naciones (pp102-103).Igualmente Villagrasa (2003, pág.13) refiere que la globalización es un proceso complejo de interconexión e interdependencia financiera, económica, política y cultural que relaciona a personas, instituciones, organizaciones y naciones; y que generan nuevas formas organizativas y culturales. Su dinámica propia es "la ampliación, profundización y aceleración de la interconexión mundial en todos los aspectos de la vida social contemporanea, desde lo cultural hasta lo criminal; desde lo financiero hasta lo espiritual" . Sin duda la globalización es hoy una realidad de grandes repercusiones en la vida del hombre, marcada por el ilimitado flujo de mercancías, capitales y personas que favorecen el libre comercio, han hecho del mundo un mercado único, no obstante, existen disyuntivas acentuadas por las diversidad de opiniones en torno a este proceso.

Por un lado, hay quienes dicen que la globalización ha generado riqueza $\mathrm{y}$ bienestar sin precedentes, por otro las corrientes detractoras, señalan que la globalización ha propiciado grandes desigualdades socioeconómicas, que no sólo se han mantenido, si no que se han agudizado; tal es el caso de la pobreza, de los niveles bajo de ingresos y crecimiento.

Estas diferencias toman importancia en virtud de que las grandes empresas transnacionales $\mathrm{y}$ organismos internacionales, son quienes imponen las reglas del juego a todo el mundo, favoreciendo sus intereses. Debemos tener en cuenta tanto los efectos positivos, como los negativos.

\section{Objetivos}

A) Evaluar las medidas tomadas ante la crisis mundial y su impacto en las finanzas públicas, partiendo de lo general a lo particular, enfocándonos en México y haciendo un exhaustivo análisis estadístico para profundizar y contrastar los resultados. B) Determinar las condiciones macroeconómicas que pueden influir en el desarrollo de una crisis, a través del análisis documental de diversas variables macroeconómicas, para así finalmente interpretar los resultados derivados de la crisis. 


\section{MATERIALES Y MÉTODOS}

Para el logro de los objetivos anteriores se llevó a cabo una investigación documental, mediante la descripción del tema, análisis de la información recabada, y la elaboración de conclusiones, esto por medio del método deductivo.

Se utilizó información pública de diferentes instituciones nacionales e internacionales, además de revisión bibliográfica de autores que han tratado previamente el tema. La crisis mundial se puede estudiar desde varias perspectivas y desde varios elementos, por eso se hace hincapié en México y en el efecto que tienen sobre las finanzas publicas.

\section{RESULTADOS Y DISCUSIÓN}

La globalización en el contexto internacional Efectos positivos de la globalización

Aunque es complejo identificar a las naciones que han logrado éxito en termino de crecimiento económico y mejores niveles de vida, es válido afirmar que los países que se abren al resto del mundo y que llevan a cabo reformas con la idea de aprovechar las oportunidades que ofrece la globalización, generalmente se benefician de la elección que han hecho a lo largo del tiempo, de acuerdo a lo siguiente:

1. La globalización ha ampliado el campo de acción en el que se opera, generando nuevas oportunidades para los ciudadanos.

2. El tamaño del mercado, donde se comercializan los productos se ha incrementado.

3. La globalización permite el mejor uso de los recursos, para la producción de bienes y servicios de una demanda alta, y por ende, de precios altos; es decir, el valor de la producción puede aumentar respecto a los recursos productivos.

4. Es posible comprar insumos, bienes de capital, bienes intermedios y de consumo, donde sean más baratos y de mejor calidad.

5. La productividad del trabajo se incrementa dada las mejores condiciones de tecnología, nuevas formas de administración y mejores herramientas de trabajo.

6. Además, los países pueden apoyarse del capital externo, rompiendo la rígida restricción que impone la disponibilidad del ahorro interno.

7. La globalización alienta $\mathrm{u}$ obliga a que los países sean más productivos, en función de la competencia externa.

Un país con orientaciones flexibles y transparentes, con una política económica inteligenteajustadaa sus propias condiciones, puede beneficiarse enormemente de la globalización; sin embargo, no todos los países pueden ser lo suficientemente soberanos, ya que por necesidad de financiamiento tienen que atender directrices de organismos internacionales, tales como: Fondo Monetario Internacional (FMI), Banco Mundial (BM) y Organización Mundial de Comercio (OMC).

Estos organismos dieron prioridad a la economía de mercado y construyeron un sistema económico susceptible de apoyar el desarrollo de los países pobres; pero, en realidad crearon un régimen comercial global al servicio de sus propios intereses corporativos y financieros, perjudicando así a los países más pobres del mundo.

Efectos negativos de la globalización.

La globalización ha sido perversa para

El banco mundial define a la pobreza como vivir con menos de dos dólares al día; pobreza absoluta o extrema es vivir con menos de un dólar al día. 
el trabajador que ha perdido su fuente de empleo, desplazado por los avances tecnológicos, y en su caso por mano de obra barata; el agricultor ha visto caer el precio de sus cosechas, en función de la elevada oferta de productos altamente subvencionados, similares o complementarios; y el empresario se ha visto en la necesidad de cerrar su empresa debido a que sus productos no pueden enfrentar la competencia externa.

En la misma retorica, se ha dado una marcada disparidad en la distribución del ingreso, se crea riqueza pero hay demasiados países y gente que no comparten sus beneficios; además las corrientes financieras superan con mucho a los flujos reales de la economía de cada Estado. En la actualidad los elevados costos de la desigualdad y la pobreza han implicado consecuencias sociales como la violencia y la inseguridad pública.

Las cifras absolutas de pobreza han aumentado a lo largo de las dos últimas décadas en los países en vías de desarrollo, alrededor del 40\% de los 6,500 millones de habitantes del mundo vive en la pobreza, una sexta parte (877 millones), vive en pobreza extrema. El mayor fracaso de la pobreza lo representa el continente africano, contando con aproximadamente un 50\% de la población en extrema pobreza.

La globalización, de acuerdo a Stiglitz (2009, pp18-39) ha sido mal gestionada, ya que, ha mostrado la pérdida de buena parte de la soberanía para muchas naciones y de su capacidad para tomar sus propias decisiones en cuestiones claves que afectan el bienestar de sus soberanos. Aunque los defensores de la globalización han asegurado que todos los países se beneficiarían económicamente, existen pruebas suficientes, tanto en países desarrollados y como en los en vías de desarrollo, en ambos casos hay muchos ciudadanos que han salido afectados.

La actual crisis económica es muestra de ello, ya que, el sistema economico (globalizador) con el que se ha presionado a los paises en vias de desarrollo, ha sido, inadecuado y a menudo muy perjudicial, además ha sido el principal desafio de la liberalización comercial y financiera, dadas las dos dos fuerzas motrices de la globalización: el comercio y la corriente de capitales.

\section{Desequilibrios globales}

Durante los diez años anteriores, los desequilibrios mundiales han sido un fenómeno de la economía mundial. Las características principales son el déficit sostenido de cuenta corriente en Estados Unidos, el Reino Unido, Australia, etc., mientras que China y otras economías emergentes de Asia, Japón, Alemania así como otras potencias mundiales en la manufactura, y como los miembros de la OPEP suelen registrar a largo plazo un superávit en la cuenta corriente. Los datos muestran que a pesar de que los EE.UU. han experimentado un déficit en la cuenta corriente desde los años ochenta, su alcance se ha mantenido relativamente en un nivel estable. La proporción del déficit se ha ampliado cada año después de la crisis financiera de Asia, y actualmente es el país con el mayor déficit de una cuenta corriente, la cantidad del déficit de la cuenta corriente mundial se sitúa en el 65\%. Por el contrario, la escala del superávit en cuenta corriente de países emergentes de Asia ha aumentado después de la crisis.

A largo plazo superávit en cuenta corriente de los países productores de petróleo (OPEP) ha sido posible por el aumento de los precios del petróleo y que conduce a las ventas de petróleo los ingresos. Japón como un país desarrollado ha experimentado una 
situación más especial. Aunque después del "Acuerdo de Plaza" del yen la apreciación de los estallidos de burbuja de activos han continuado, poniendo al país en una trampa de liquidez a largo plazo, con una atonía de la inversión y una estructura de tasa de natalidad baja. El envejecimiento también hizo caer la tasa de ahorro del $34 \%$ en 1990 , al $28 \%$ en 2007, sin embargo, debido a los continuos avances de la productividad del trabajo doméstico, la historia de su superávit en cuenta corriente aún se mantiene después de dos o tres décadas. Por ejemplo, en el año 2000 el superávit en cuenta corriente como porcentaje del PIB aumentó de $2.56 \%$ y luego, gradualmente, se elevó a $4.82 \%$ en 2007. De acuerdo con la ecuación de ingresos de la identidad nacional, la balanza de un país sobre la cuenta corriente este es igual al ahorro menos la inversión, es decir, CA = S-I. Por lo tanto, el superávit exterior por cuenta corriente (déficit) debe estar asociado con un alto ahorro interno (bajo nivel de ahorro). Después de la crisis financiera asiática, China y otras economías emergentes de Asia han elevado ahorros, mientras disminuyen los patrones de consumo y el resultado fue un superávit en cuenta corriente. Los Estados Unidos, Gran Bretaña y otros países desarrollados, en cambio aumentaron su consumo y la redujeron sus ahorros lo que provocó un déficit a largo plazo de la cuenta corriente. El ahorro de ex altos y bajos patrones de consumo de comportamiento condujo a un exceso de ahorro global, entonces el déficit a largo plazo enormes comercial de EE.UU. proporcionó servicios de financiación (Bernanke, 2005), y bajó el nivel de las tasas de interés de EE.UU.

La crisis global

La división del trabajo en relación a la crisis
La economía mundial, vive la mayor contracción de la actividad económica en siete $\mathrm{u}$ ocho décadas. Las generaciones adultas y jóvenes que ahora integran la población económicamente activa, así como quienes toman la decisiones en materia política y económica en las diferentes naciones, no se habían encarado un desafió de la magnitud y profundidad como la actual crisis financiera.

Los países en la era de la globalización aprovechan más plenamente sus ventajas comparativas, lo que resulta en diferencias entre países en relación al superávit en cuenta corriente . La globalización tiene una fuerte tendencia a especializarse; los países realizan actividades económicas específicas en que tienen ventajas comparativas (Xu Jianwei y Yao Yang, 2010)

Con la aceleración de la integración económica mundial y la profundización de la división internacional del modelo de trabajo, las empresas multinacionales en los países desarrollados, los países que no son capaces de lograr la ventaja comparativa en su producción tradicionales, industrias de alta tecnología, han transferido parte de la mano de obra barata a China, otros países asiáticos y Latinoamérica. Por lo tanto, el Centro Global de Manufactura (Centro de creación de riqueza real) y el centro financiero y monetario han sido separados. Los Estados Unidos y el Reino Unido han trasladado a China su producción por tener una ventaja comparativa como un foco para la industria financiera y la economía virtual de otros y el sector terciario (Zhang Yansheng, etc, 2010), mientras que Japón, Alemania y otros países tradicionalmente fuertes en producción lograron un valor agregado bajo la producción de trasladarse a la región de Asia, trasladando sus propias 
ventajas y valor añadido de manufactura de alto valor de bienes de consumo a China y otros países emergentes de manufactura en el mundo división del trabajo y de gama baja de la cadena de valor (Xu Yang Jianwei y Yao, 2010), en esta división internacional del modelo de trabajo, Japón, Alemania, así como China y otros países asiáticos en desarrollo han aumentado la dependencia de la demanda de las exportaciones de bienes de los Estados Unidos y Gran Bretaña.

El propósito para reactivar la economía de Estados Unidos

Con el propósito de reactivar la inversión y el crecimiento de la economía norteamericana, el Fondo de Reserva Federal de los Estados Unidos de Norteamérica (FED), disminuyó drásticamente las tasas de interés .

Por lo que de enero a noviembre del 2001 la tasa de interés se redujo sistemáticamente del $6.5 \%$ 1.75\% . El presidente de la FED, Alan Greenspan, intentaba reactivar así la economía estadounidense aumentando el crédito hipotecario y de consumo.

Sin embargo, la medida que parecía ser la panacea de la economía estadounidense tuvo efectos adversos, tal como lo afirma Joseph Stiglitz, la reducción de las tasas de interés no aumentaron las inversiones productivas.

Con los bajos intereses en el mercado hipotecario, una cantidad mayor de personas norteamericanas pudieron adquirir su propia vivienda, generando con ello una situación de euforia, que expande la demanda de casa para habitarla, o bien con propósitos

Los datos estadísticos de la economía estadounidense citados están obtenidos de fuentes oficiales: Federal Reserve System, Bureau of Economic Analysis, Bureau of Labor Statistics.

Una hipoteca subprime es una modalidad crediticia que se caracteriza por tener un nivel de riesgo superior a otros préstamos que ofrecen las instituciones bancarias, ya que se dedican a otorgar créditos hipotecarios a personas que presentan un alto riesgo, por esa razón las empresas subprime aseguran su inversión por medio de altos intereses o del embargo de la propiedad que implica la especulativos.

En este contexto, el sistema financiero ofreció sus servicios de alto riesgo a la mayor cantidad de personas, sin observar los historiales crediticios (exigencia mínima de requisitos, no requerimiento de pruebas de ingresos, esquemas de pago iniciales mínimos). Esta categoría de deudores, son denominados como subprime . Esto implicó para las entidades financieras, mayores riesgos de incumplimiento y aunado a esto, incrementos a su rentabilidad, debido a que otorgaban créditos con altas tasa de interés (por lo general eran hipotecas con tasas de interés ajustable).

La burbuja financiera y la crisis mundial El auge inmobiliario atrajo a los grandes bancos de inversión que vieron una oportunidad enorme de ganancias a través de la aplicación de nuevas herramientas de ingeniería financiera (swaps), para empaquetar los créditos subprime y dividirlos en segmentos. A través de la perspectiva de Tustain (2007) los prestamistas hipotecarios se deshicieron del riesgo de impacto (default) de los deudores suprime.

Es así como las hipotecas fueron empaquetadas en bonos llamados MortgageBaked Securities (MBS) y se vendieron a otras organizaciones financieras más fuertes, estas creaban derivados financieros que las vendían a otras instituciones financieras aún más fuertes, que a su vez los empaquetaban en otros derivados y los volvían a vender. Así se difundieron por todo el mundo, las calificadoras de riesgos contratadas por

hipoteca.

La consiguiente elevación de las tasas hipotecarias (del 5.05\% a comienzos de 2004 al $6.74 \%$ en junio de 2007 para créditos a 30 años) junto con la de los precios de los alimentos y de los combustibles produjo dos efectos indeseables: los prestatarios dejaron de pagar sus hipotecas: a mediados de 2007 las originadas a principios de 2006 tenían una morosidad del 23\%; y los compradores de vivienda se desanimaron, el stock de casas sin vender aumentó y se produjo una crisis inmobiliaria: en 2007 
estas instituciones financieras, certificaban su seguridad.

Por la expansión al consumo y la construcción, se generó un aumento de la producción y de las importaciones de materias primas y manufacturas. Estas últimas suministradas principalmente por China e India, que demandaron más materias primas, redujeron su pobreza y demandaron más alimentos y combustibles (Ferrari, 2008, pág. 57). Situación que en EU, generó un déficit comercial, por lo que las autoridades monetarias reaccionaron aplicando una política de administración de tasas de interés, siendo así que la Reserva Federal decide aumentarlas para reducir la demanda interna y la inflación. Entre junio de 2004 y septiembre de 2007 la FED elevó su tasa del $1.0 \%$ al $5.25 \%$.

En otro contexto, la guerra de Irak redujo la oferta de petróleo. Los subsidios a los biocombustibles y la alta rentabilidad petrolera disminuyeron las tierras para producir alimentos $\mathrm{y}$, por tanto, la oferta de alimentos. Ocurrió lo que era obvio: los precios internacionales de los alimentos se elevaron y se sumaron a también crecientes precios del petróleo y los metales. Con ellos, sus productores y los que les vendían bienes y servicios tuvieron su bonanza, particularmente en América Latina.

Ante estas condiciones (aumento de la tasa de interés), el mercado inmobiliario

la venta de viviendas nuevas cayó en un 26\% y la de viviendas usadas en un $13 \%$.

Éstos son créditos con un nivel de riesgo superior a la media. Es decir, son créditos concedidos por bancos cuyos deudores tienen una posibilidad de entrar en mora o impago superior a la media. Por ello, los bancos cobran un tipo de interés superior en estos créditos. La mayoría de créditos subprime son de tipo hipotecario, es decir, están asocia-dos a la adquisición de una vivienda o un bien inmobiliario por parte del deudor.

Lehman Brothers, fue el cuarto banco de inversión de Estados Unidos, quien fue declarado en quiebra en el mes de septiembre de 2008, tras 158 años de actividad ante el fracaso de las negociaciones con las dos entidades que en un principio comienza a cambiar y muestra los primeros signos de desaceleración .

Finalmente, esto hizo que la crisis iniciará a finales de 2007 como una crisis de hipotecas subprime, que se extendiera a diferentes bancos internacionales que apostaban a ganancias significativas, derivadas de los prestamos empaquetados por un conjunto de acciones cuyo efecto colateral se daba en especulación.

La contracción del crédito a partir del 2008, estuvo precedida por una explosión de préstamos a corto plazo, que pasaron de 500 mil millones de dólares a 1.6 billones de dólares operados por Lehman Brothers y Bear Stearns , (Girón, 2010, pág. 20).

Cabe señalar, de acuerdo a Soros (2008) que el intervencionismo de Estados Unidos de Norteamérica abarca desde la nacionalización de instituciones y la compra de activos tóxico (contaminados) hasta el otorgamiento de créditos y ganancias.

Los casos más notables son los de City Group , AIG , Fannie Mae, Freddie Mac , General Motor y Chrysler en Estados Unidos; Northern Rock, Royal Bank of Scotia en Inglaterra; UBS en Suiza, así como operaciones de rescates en Alemania y otros países.

De acuerdo a lo anterior, los seis bancos centrales (Banco de Japón, Reserva Federal Estadounidense, Banco Central Europeo

\footnotetext{
se perfilaban como posibles compradores, Bank of América y el grupo británico Barclays.

Bear Stearns, el quinto banco de inversión más grande de Estados Unidos.

Los activos tóxicos no son otra cosa que las inversiones bursátiles sacudidas por la crisis de las hipotecas basura o en su defecto las subprime, o en su defecto préstamos hipotecarios para clientes de muy alto riesgo, dado que son otorgados a personas con dudoso historial crediticio (http://eleconomista.com.mx, 2009).

Citigroup reconoce pérdidas de más de 5 mil millones de dólares en el primer trimestre del 2007, y cierra este ejercicio con la peor cuenta trimestral, perdiendo 10 mil millones de dólares.

La Reserva Federal salva a la aseguradora AIG con una inyección
} 
(BCE), Banco de Canadá, Banco de Inglaterra y Banco Nacional Suizo), usaron sus instrumentos ordinarios de acción frente a la crisis, por un lado redujeron las tasas de interés y pusieron a disposición del sector financiero una creciente liquidez, por otra parte, abrieron acceso con muchas facilidades a nuevos agentes financieros, creando swaps en moneda extranjera o apoyos a la liquidez cambiaria (Ibarra, 2009, pág. 18).

Las instituciones financieras mencionadas anteriormente, echaron mano de medidas extraordinarias: adquieren acciones o partes sociales de empresas (Japón, Inglaterra, Estados Unidos, India y Hong Kong), compran deuda privada (Japón, Inglaterra, Estados Unidos y Canadá), toman instrumentos de deuda pública (Estados Unidos, Inglaterra y Suiza) o inyectan recursos al rescate de negocios empresariales (Japón, Estados Unidos, Inglaterra y Suiza).

La inflación impulsada por los precios internacionales, se aceleró. En Estados Unidos fue del $2.6 \%$ en 2006 , del $4.1 \%$ en 2007 y del $5.6 \%$ a julio de 2008 . Sólo con la caída de los precios internacionales la tasa mensual comenzó a bajar: $0.8 \%$ en julio de $2008,-0.1 \%$ en agosto, $0 \%$ en septiembre. En el contexto de la crisis internacional las expectativas de recesión se generalizaron, la mayoría de los inversionistas priorizaban garantizar sus recursos antes de arriesgarlos. La incertidumbre interna y externa, (producto de la crisis), aumenta la percepción del riesgo e induce al movimiento de capitales golondrina (capital de corto plazo). Paradójicamente, el Estado interviene;

\footnotetext{
financiera de 85,000 millones de dólares en septiembre del 2008. El 06 de agosto de 2008 Freddie Mac anuncia pérdidas de 972 millones de dólares, un mes después se nacionaliza junto con Fannie Mae, para proteger el mercado, lo que suponía la mayor intervención gubernamental de la historia de Estados Unidos.
}

El gobierno británico nacionaliza a Northern Rock, en febrero primero reconoce la gravedad de la situación y segundo anuncia la instrumentación de un programa masivo de rescate por $700 \mathrm{mil}$ millones de dólares.

Los efectos de la crisis en América Latina. Auge de la Economía Latinoamericana En el caso de América Latina, se dio un parte aguas a partir del 2009, pero antecediéndolo a esto en el periodo de 2003 y 2008 esta región económica alcanzó un crecimiento a una tasa media cercana al $5 \%$ anual (con un crecimiento del PIB por habitante mayor al $3 \%$ anual).

Asimismo, la coyuntura marcadamente favorable del periodo 2003-2007, basada en una combinación inusual de auge financiero, bonanza excepcional de precios de los productos básicos (Ocampo, 2009, pág. 10), derivándose una mejora en las cuentas externas, que dio como resultado una intensa acumulación de reservas internacionales, el siguiente gráfico muestra el aumento de los términos de intercambio que experimento América Latina como un todo entre 2002 y

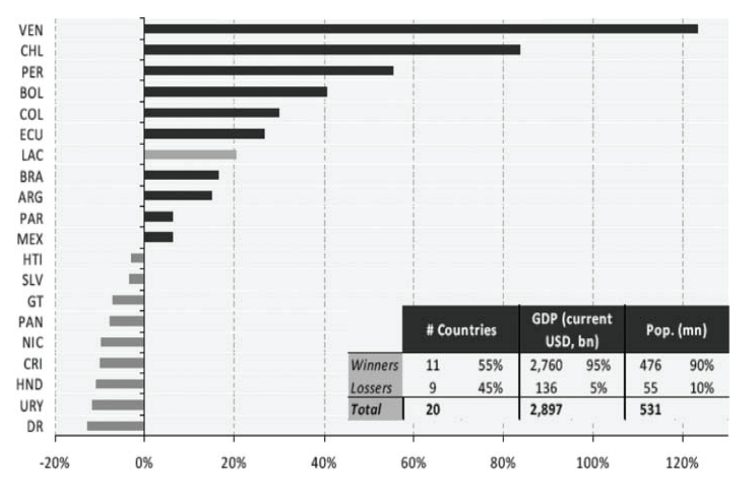

Figura 1. Términos de intercambio de países de LAC seleccionados cambio entre 2002 y 2007 - en \%

Fuente: LCRCE (World Bank) en base a CEPAL

de 2008

Se unen para realizar una inyección de capital en dólares y apaciguar la crisis financiera, esto trascurre el 18 de septiembre del 2008.

Datos de la Comisión Económica para América Latina 
2007, que fue superior al $20 \%$.

Si observamos la grafica anterior podemos inferir que no todos los países de América Latina obtuvieron resultados favorables. El 55\% de ellos resultaron ganadores por tratarse de naciones exportadoras de alimentos y algunos productos industriales; el resto de los países (45\%) sufrieron caídas que no afectaron significativamente el desempeño promedio de la región, dado que por ser los países más pequeños de la región, se vieron perjudicados por el aumento del precio del petróleo y de algunos alimentos, dado que son importadores netos de estos productos. Como se puede observar en la mayoría de los países latinoamericanos parte del aumento se explica por el crecimiento del precio de las commodities (Rozenwurcel \& Rodríguez, 2009, pág. 6).

En este orden de ideas, como señalan Rozenwurcel y Rodríguez $(2009,8)$ gran parte de los países latinoamericanos no presentaron problemas en la balanza de pagos, dado que lograron compensar la caída del intercambio con la entrada neta de divisas por el lado del comercio con un espectacular ingreso de remesas de trabajadores radicados en el extranjero, que en países como Honduras, Guyana, Haití, Jamaica, El

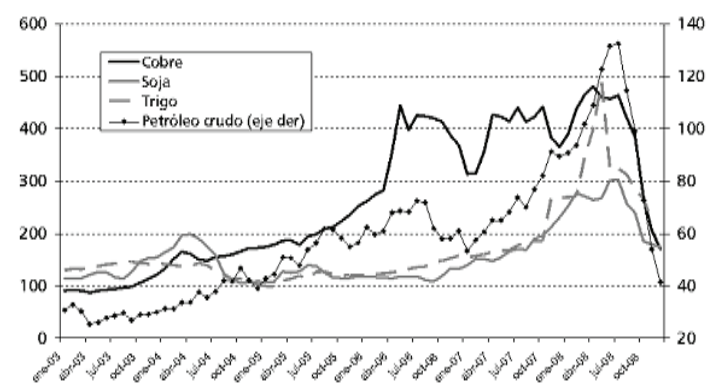

Figura 2. Precios de commodities (Cobre, Soja, y Trigo: índice 2000-100) Petróleo: precio promedio del barril de crudo en dólares corrientes

Fuente: elaboración propia en base a IFS (IMF)
Salvador y Nicaragua representaron entre el $15 \%$ y el $20 \%$ del PIB en 2007; en cambio, en naciones como Guatemala República Dominicana, Ecuador, Bolivia y Belice, las remesas representaron de un $5 \%$ a un $10 \%$ del PIB latinoamericano.

Nota: PIB en dólares corrientes según la Comisión Económica para América Latina y el Caribe (CEPAL); mercado interno de capitales según el Banco de Pagos Internacionales. Los datos se refieren a las siete economías más grandes (Argentina, Brasil, Chile, Colombia, México, Perú y República Bolivariana de Venezuela).

* A estas cuentas se les resto el valor de los pasivos con el Fondo Monetario Internacional.

Como podemos identificar, la naturaleza de las corrientes financieras de las siete principales economías de América Latina (Argentina, Brasil, Chile, Colombia, México, Perú y Venezuela), durante el auge económico, se denotan dos cambios importantes. El primero, es el cambio de los activos, principalmente en el rubro de las reservas internacionales, pero también en el renglón de las inversiones directas y de cartera en

el exterior. El segundo, es el fuerte cambio de la composición de los pasivos, caracterizada esencialmente por la reducción del endeudamiento y la considerable presencia de pasivos de cartera accionarios (Ocampo, 2009, pág. 19).

Además la acumulación de reservas parecieran ser bastantes solidas, en comparación con los pasivos de deuda. La contrapartida de esta situación sería el auge de los mercados internos de capitales. Esta situación, representó el principal activo que 
EFECTOS DE LA CRISIS DE 2007 EN LAS FINANZAS PÚBLICAS DE MÉXICO

Cuadro 1. América Latina (siete países): Hoja de balance externo (en porcentajes del PIB a precios corrientes.

\begin{tabular}{|c|c|c|c|c|c|c|c|}
\hline & 2001 & 2002 & 2003 & 2004 & 2005 & 2006 & 2007 \\
\hline \multicolumn{8}{|l|}{ Activos } \\
\hline Totales ${ }^{\mathrm{a}}$ & 26,5 & 29,7 & 31,9 & 31,5 & 31,4 & 32,4 & 37,5 \\
\hline Inversión directa en el exterior & 5,8 & 6,9 & 7,0 & 7,2 & 7,0 & 7,5 & 7,9 \\
\hline Activos de cartera & 2,1 & 2,4 & 3,2 & 3,2 & 3,5 & 3,9 & 4,8 \\
\hline Derivados & 0,0 & 0,0 & 0,0 & 0,1 & 0,0 & 0,0 & 0,0 \\
\hline Otras inversiones & 12,1 & 13,3 & 13,4 & 12,6 & 11,4 & 10,8 & 12,5 \\
\hline Reservas internacionales $^{\mathrm{a}}$ & 6,6 & 7,1 & 8,3 & 8,5 & 9,5 & 10,0 & 12,3 \\
\hline \multicolumn{8}{|l|}{ Pasivos } \\
\hline Totales $^{\mathrm{a}}$ & 62,4 & 65,4 & 70,4 & 66,4 & 61,5 & 60,3 & 65,6 \\
\hline Inversión extranjera directa & 24,5 & 25,5 & 28,6 & 28,1 & 26,7 & 25,6 & 27,2 \\
\hline Pasivos de cartera & 19,8 & 20,1 & 23,1 & 22,9 & 22,8 & 23,8 & 28,0 \\
\hline Acciones & 5,5 & 4,9 & 7,2 & 8,4 & 10,4 & 13,0 & 16,9 \\
\hline Deuda & 14,3 & 15,2 & 15,9 & 14,5 & 12,3 & 10,9 & 11,1 \\
\hline Derivados & 0,0 & 0,0 & 0,0 & 0,1 & 0,1 & 0,2 & 0,3 \\
\hline Otras inversiones $^{\mathrm{a}}$ & 18,0 & 19,8 & 18,6 & 15,4 & 11,9 & 10,7 & 10,2 \\
\hline Activos - pasivos & $-35,8$ & $-35,7$ & $-38,4$ & $-34,9$ & $-30,1$ & $-27,9$ & $-28,1$ \\
\hline Inversión directa & $-18,8$ & $-18,6$ & $-21,6$ & $-20,9$ & $-19,7$ & $-18,0$ & $-19,2$ \\
\hline Financieros & $-17,1$ & $-17,1$ & $-16,8$ & $-14,0$ & $-10,4$ & $-9,9$ & $-8,9$ \\
\hline Reservas como porcentaje de la deuda & 20,3 & 20,4 & 24,0 & 28,3 & 39,1 & 46,5 & 57,9 \\
\hline Reservas como porcentaje de pasivos de cartera & 33,1 & 35,5 & 35,9 & 37,0 & 41,6 & 42,1 & 44,0 \\
\hline Mercado interno de capitales como porcentaje del PIB & 34,2 & 32,1 & 38,7 & 39,8 & 43,8 & 44,5 & 49,1 \\
\hline \multicolumn{8}{|l|}{ Activos - pasivos financieros } \\
\hline Argentina & $-0,3$ & 19,8 & 20,1 & 22,0 & 29,5 & 26,2 & 29,0 \\
\hline Brasil & $-34,9$ & $-36,4$ & $-35,2$ & $-31,0$ & $-24,1$ & $-23,8$ & $-28,9$ \\
\hline Chile & $-3,2$ & $-1,5$ & 3,9 & 13,5 & 17,3 & 27,6 & 42,7 \\
\hline Colombia & $-13,8$ & $-13,6$ & $-14,5$ & $-10,2$ & $-5,2$ & $-3,1$ & $-0,9$ \\
\hline México & $-17,6$ & $-16,7$ & $-18,6$ & $-18,4$ & $-19,3$ & $-21,1$ & $-16,7$ \\
\hline Perú & $-29,4$ & $-27,9$ & $-26,4$ & $-21,3$ & $-14,4$ & $-7,6$ & $-6,8$ \\
\hline Venezuela, Rep. Bol. de & 23,9 & 35,9 & 48,7 & 44,6 & 49,3 & 50,8 & 51,3 \\
\hline \multicolumn{8}{|l|}{ Reservas como porcentaje de pasivos de cartera } \\
\hline Argentina & 2,2 & $-14,2$ & 1,7 & 19,6 & 67,6 & 72,8 & 93,4 \\
\hline Brasil & 18,1 & 13,1 & 13,6 & 15,7 & 23,1 & 28,6 & 35,4 \\
\hline Chile & 142,4 & 145,8 & 108,3 & 98,9 & 93,3 & 98,3 & 83,6 \\
\hline Colombia & 78,8 & 88,1 & 84,2 & 91,8 & 102,7 & 96,8 & 114,6 \\
\hline México & 30,8 & 41,6 & 42,7 & 39,0 & 35,8 & 30,0 & 29,0 \\
\hline Perú & 131,1 & 125,4 & 105,2 & 114,4 & 91,7 & 98,2 & 97,5 \\
\hline Venezuela, Rep. Bol. de & 131,1 & 125,4 & 105,2 & 114,4 & 91,7 & 98,2 & 97,5 \\
\hline
\end{tabular}

Fuente: elaboración propia sobre la base de datos del Fondo Monetario Internacional (FMI), Estadisticas financieras internacionales (en línea).

distinguió a la región para hacer frente a condiciones internacionales adversas.

Respecto al comercio internacional, la región experimentó un periodo de expansión importante que obedeció precisamente a la bonanza de precios de los productos básicos y que favoreció a los países exportadores

Pasivos que incluyen las inversiones realizadas en los países de la región, por los fondos de inversión internacional. netos de alimentos (sobre todo al cono sur), productos mineros (Brasil, Chile, México, Perú, y Venezuela), y energía (Colombia, Ecuador, México y Venezuela). El marcado aumento de precios de los productos básicos culminó a mediados de 2008, seguido de una fuerte baja en la segunda mitad del año. 


\section{Aspectos negativos de la crisis}

Como se ha señalado, a finales del 2007 se da el estallamiento de la crisis mundial, gracias al auge de los flujos financieros que exhiben una notable volatilidad. La gestación de la crisis, obedece a esquemas especulativas de los mercados financieros internacionales, de tal suerte que los mercados de capitales se expandieron con una intensa diversificación de instrumentos opacos y propensos a la especulación (Ffrench-Davis, 2009, pág.68). De ahí que la fuerte presencia de centros financieros internacionales extraterritoriales y paraisos fiscales, tuvieron la oportunidad de realizar multiples operaciones financieras, sin la más minima regulación, situacion que estimuló la evasiva, no sólo de la regulacion financiera nacional, sino también de los controles de capital y de los impuestos.

Es necesario señalar, que la abundancia de financiamiento se redujo desde el tercer trimestre de 2007, coincidiendo con la primera fase de la crisis financiera en los Estados Unidos. A su vez, a mediados de 2008 se inició la baja de precios de los productos básicos. Pero fue el colapso financiero mundial de mediados de septiembre de 2008 lo que desencadenó los cambios más profundos, al paralizar el crédito, elevar marcadamente los márgenes de riesgo, convertir la caída de los precios de los productos básicos en un desplome y desencadenar una profunda recesión en el mundo industrializado. Incluso las economías latinoamericanas que habían mantenido un alto y aun creciente dinamismo hasta el tercer trimestre de 2008, como Brasil y Perú, se estrellaron contra la pared (Ocampo, 2009, pág. 10). A lo largo de 2008, varias economías de la región experimentaron una desaceleración importante, entre ellas Colombia, México, Republica Bolivariana de Venezuela y casi todas las economías más pequeñas de Centroamérica y el Caribe.

Los países de América Latina y el Caribe se vieron afectados por el fuerte choque externo. Las cifras para 2009, comparadas con las del mismo período de 2008, muestran una caída estimada de entre el $35 \%$ y el $45 \%$ en los flujos de IED, una disminución de entre el $5 \%$ y el $10 \%$ en las remesas, una reducción del $29 \%$ en los precios internacionales de los productos básicos que exporta la región $y$ del $25 \%$ en el valor de sus exportaciones.

\section{a. Remesas.}

Por otra parte, el nivel elevado de remesas de los trabajadores migrantes, también llegaba a su fin. La caída de la actividad constructora estadounidense provocó uno de los canales de transmisión de la crisis más importante, el de las remesas, dado que gran parte de los trabajadores de la construcción en EU, son migrantes mexicanos $(13,8 \%$, una cifra casi tres veces superior a la participación de mexicanos en la fuerza de trabajo de los Estados Unidos, que es del 5,1\%) (J.P. Morgan, 2008).

En todo caso, sobre la base de las estadísticas de balanza de pagos de América Latina, está claro que el periodo de crecimiento acelerado de estas culminó en 2006. En los dos últimos años han aumentado a un ritmo más pausado ( $3 \%$ medio), con una contracción moderada en 2008 en México.

Las corrientes totales de remesas hacia los países en desarrollo crecieron un $15.1 \%$ en 2008 respecto del año anterior, alcanzando los 328.000 millones de dólares. En el mismo período, los flujos hacia la región aumentaron sólo un 1.4\%.

Esto obedeció en gran medida a los efectos negativos de la recesión estadounidense en 


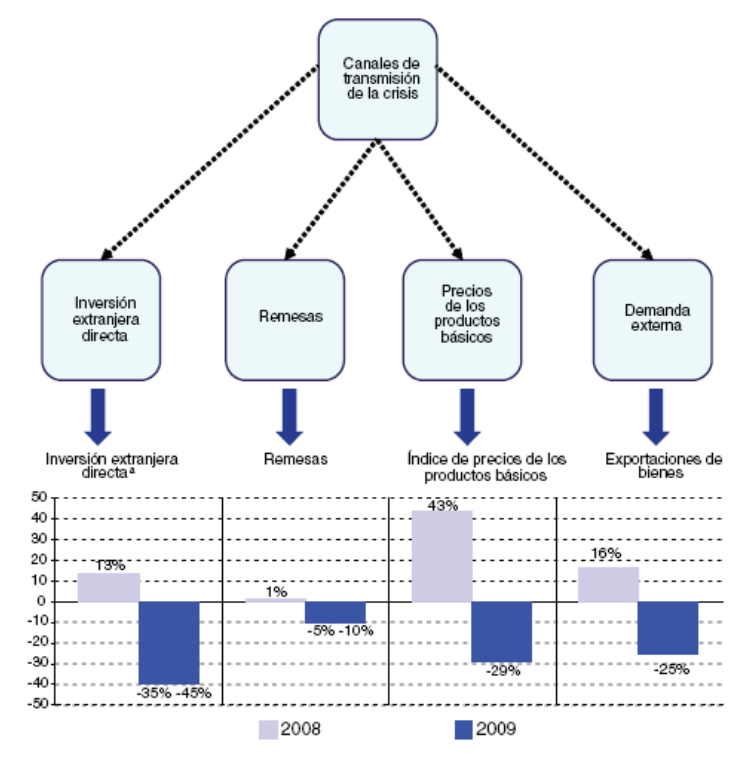

Figura 3. América Latina y el Caribe: Canales de transmisión de la crisis y magnitud del impacto en algunos rubros seleccionados, 2009. (en tasas de variación con respecto a igual periodo 2009)

Fuente: Comisión Económica para América Latina y el Caribe (CEPAL), sobre las bases oficiales de los países.

el empleo y el ingreso de los inmigrantes latinoamericanos, especialmente en el sector de la construcción. Cabe destacar que, desde 2007 en adelante, las corrientes de remesas hacia la región ya venían mostrando un comportamiento menos dinámico que las recibidas por otras regiones en desarrollo.

Por otra parte, de acuerdo con (Rozenwurcel \& Rodríguez, 2009, pág. 7), durante el 2008 se desaceleró el ritmo de ingresos de remesas a Latinoamérica y el Caribe, al tiempo que aumentaba el desempleo hispano en EU.

Según el Banco Mundial, en 2009 las corrientes de remesas hacia la región disminuirían a un rango de entre $58.000 \mathrm{y}$ 60.000 millones de dólares, lo que representa una baja del 6\% al 9\%.

\section{b. El comercio internacional.}

Aunque el volumen de comercio mundial aumentó un 9.3\% anual, duplicando con creces el incremento de la producción mundial y los precios de mercado un $3.8 \%$. Sin embargo, el ritmo de crecimiento de ambos indicadores ha sido muy sensible a los ciclos económicos $\mathrm{y}$, por ende, más volátil que el del PIB mundial. Como resultado de ello, el comercio internacional se ha convertido en un mecanismo amplificador, tanto de los periodos de auge como de los de contracción de la actividad productiva. En 2007 y 2008 se redujo significativamente, creciendo apenas un $2 \%$ en septiembre de este último año (Ocampo, 2009, pág. 17).

De hecho, los datos parciales disponibles indican que en el último trimestre de 2008 hubo una contracción del comercio mundial. Según el Banco Mundial, en 2009 disminuiría un 2,1\% y de acuerdo con el escenario pesimista de las Naciones Unidas (2009, cuadro I.1), un 3,1\%.

Cuadro 2. América Latina y el Caribe y Países en Desarrollo: Corrientes de Remesas, 20022010 (En miles de millones de dólares)*

\begin{tabular}{|c|c|c|c|c|c|c|c|c|c|c|c|}
\hline & \multirow[b]{2}{*}{2002} & \multirow[b]{2}{*}{2003} & \multirow[b]{2}{*}{2004} & \multirow[b]{2}{*}{2005} & \multirow[b]{2}{*}{2006} & \multirow[b]{2}{*}{2007} & \multirow[b]{2}{*}{2008} & \multicolumn{2}{|l|}{2009} & \multicolumn{2}{|l|}{2010} \\
\hline & & & & & & & & $\begin{array}{l}\text { Escenari } \\
\text { o base }\end{array}$ & $\begin{array}{l}\text { Escenario } \\
\text { pesimista }\end{array}$ & $\begin{array}{l}\text { Escenar } \\
\text { io base }\end{array}$ & $\begin{array}{l}\text { Escenario } \\
\text { pesimista }\end{array}$ \\
\hline $\begin{array}{l}\text { América Latina y el } \\
\text { Caribe }\end{array}$ & 28 & 37 & 43 & 50 & 59 & 63 & 64 & 60 & 58 & 61 & 57 \\
\hline $\begin{array}{l}\text { Total países } \\
\text { desarrollo }\end{array}$ & 116 & 144 & 164 & 195 & 228 & 285 & 328 & 304 & 295 & 313 & 294 \\
\hline
\end{tabular}

Fuente: Banco Mundial, Global Development Finance: Charting a Global Recovery, Washington D.C., 2009 y "Outlook for remittance flows 2009-2011: remittances expected to fall by 7-10 percent in 2009”, Migration and Development Brief, No 10, 13 de Julio de 2009.

*2008 estimación; 2009 y 2010:pronóstico. 


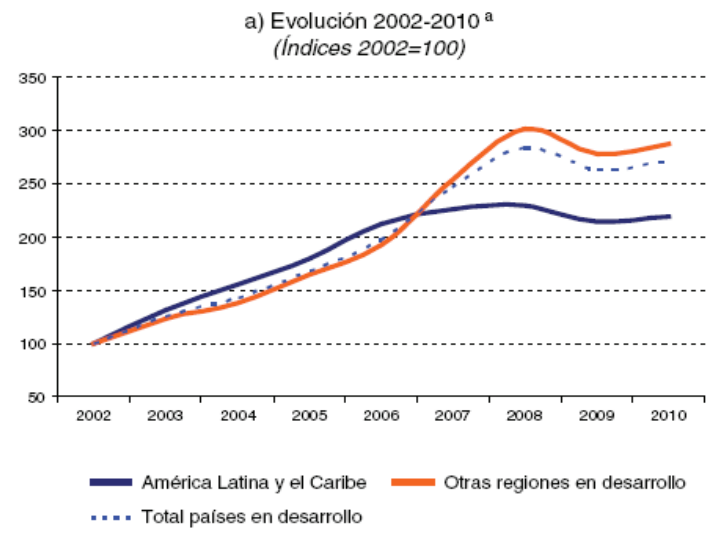

b) Tasa de variación entre 2008 y $2009^{\text {b }}$ (En porcentajes)

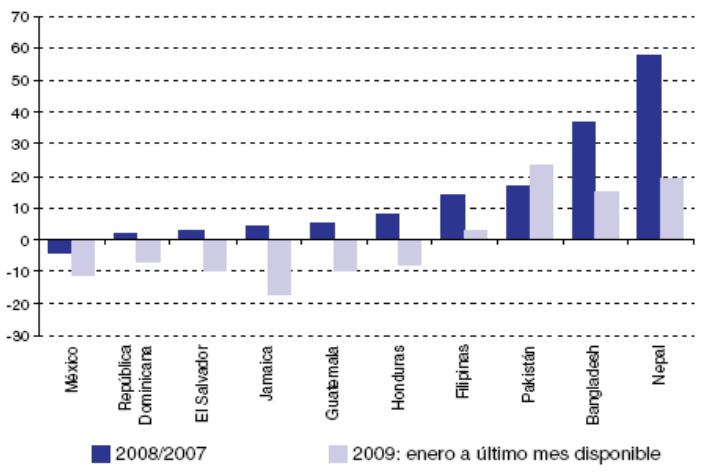

Figura 4. América Latina y el Caribe y países en desarrollo: Evolución de las corrientes de remesas durante el periodo de auge de la crisis.

Fuente: Banco Mundial, Global Development Finance: Charting a global recovery, Washington, D.C., 2009

a) Exportaciones

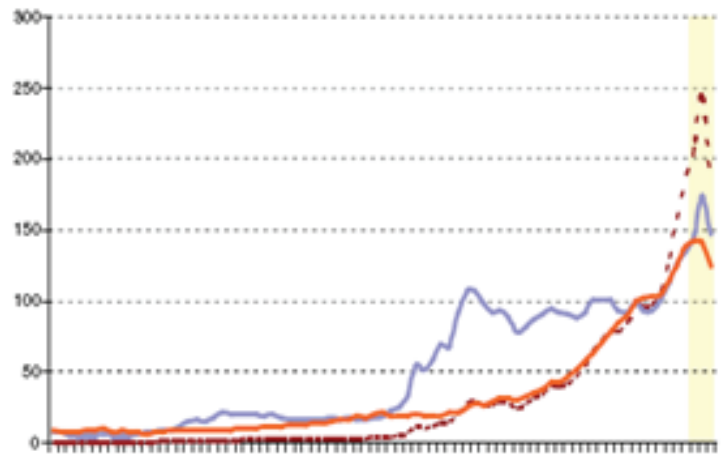

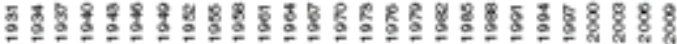

$$
\text { .... valor Precio }
$$

c) Evolución anual del precio y el volumen exportado

c) Evolución anual del precio y el volumen exportado

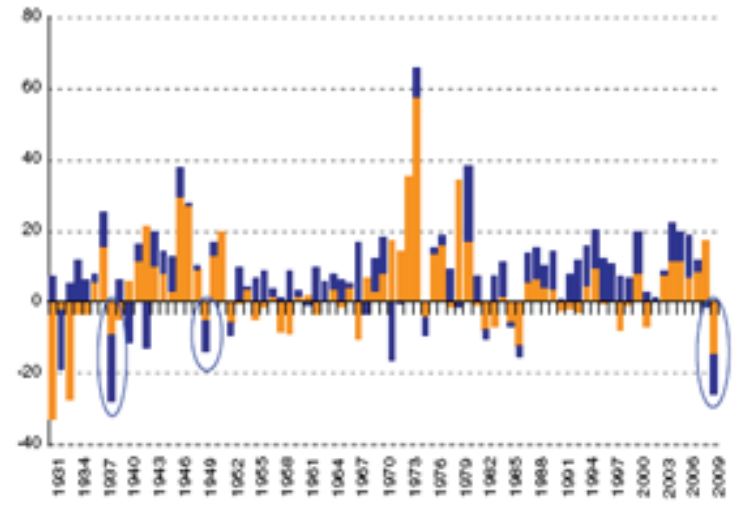

Dreclo b) Importaciones

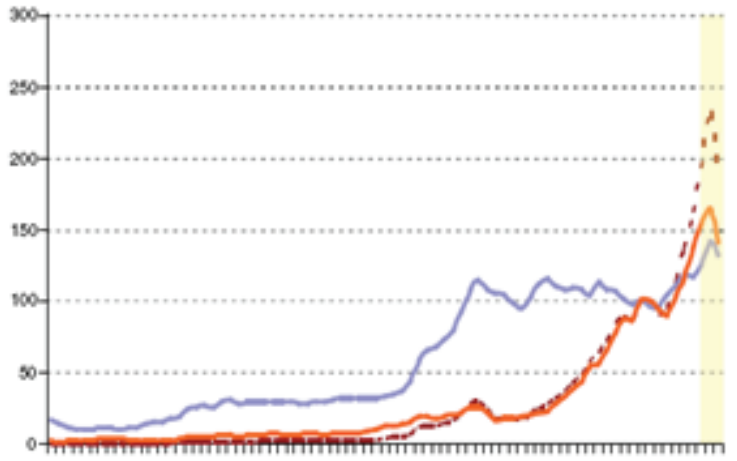

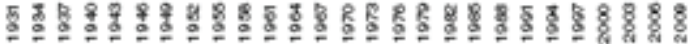

Volumen

d) Evolución anual del precio y el volumen importado

d) Evolución anual del precio y el volumen importado

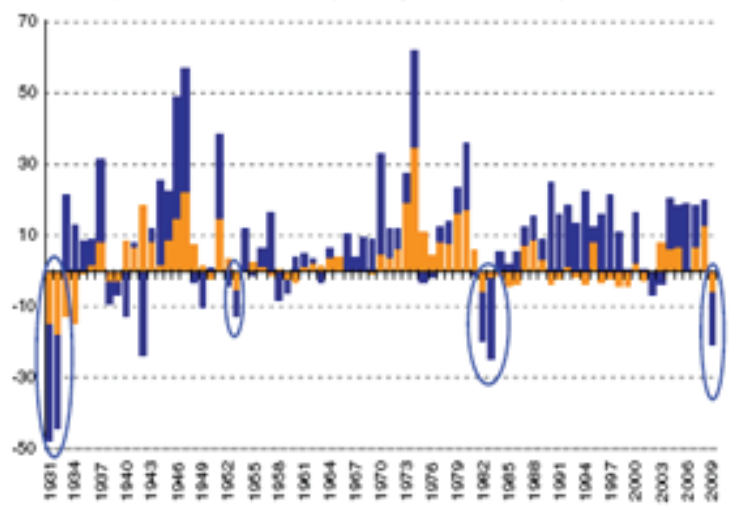

Volumen

Figura 5. América Latina y el Caribe (15 países) : Evolución del comercio de bienes, 19312009 (índices 2000=100)

Fuente: Comisión Económica para América Latina y el Caribe (CEPAL), sobre la base de cifras oficiales de los países. 
a) Niveles del índice (enero-marzo 2006=100)

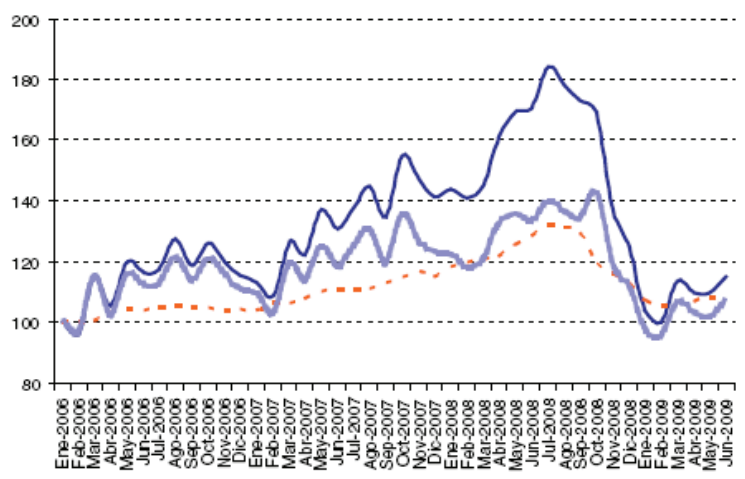

b) Variación mensual del índice en porcentajes

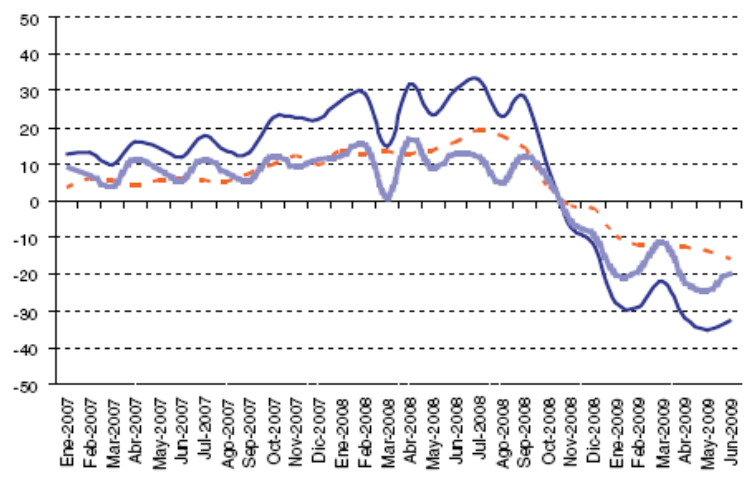

Figura 6. América Latina y el Caribe: Variación mensual del índice de comercio exterior, enero de 2006 a junio de 2009 (en niveles del índice y porcentajes)

Fuente: Comisión Económica para América Latina y el Caribe (CEPAL), sobre la base de información oficial de las oficinas nacionales de estadísticas, bancos centrales y aduanas de 15 países.

Mediante el índice de comercio exterior, que recoge la tendencia de las importaciones y exportaciones de América Latina y el Caribe, se capta con claridad el descenso sincronizado del valor y el volumen del comercio durante los períodos señalados. A fines del primer semestre de 2009, las corrientes comerciales se ubicaron en valores cercanos a los del primer trimestre de 2006. Esta baja en los niveles de comercio internacional es más pronunciada que la registrada a causa de la crisis asiática.

Entre las causas de esta desaceleración aguda, del comercio internacional, según datos de la CEPAL (2009), destacan la contracción de la demanda internacional, la disminución de los precios de algunas materias primas básicas, las dificultades del financiamiento del comercio (principalmente durante el último trimestre de 2008).

El Caribe aparece como la subregión más afectada por la baja del valor en sus exportaciones, mientras que México y Centroamérica registran las mayores disminuciones en el valor de las importaciones. En términos muy generales, se observa la variación mensual del índice de comercio exterior, de enero de 2006 a junio de 2009.

Como se percibe, la contracción del volumen de comercio, representada por un $-25 \%$, de acuerdo a la CEPAL, ha sido uno de los principales mecanismos de transmisión de la crisis hacia los países latinoamericanos y caribeños en su conjunto.

Este fenómeno, afectó especialmente a aquellos países en cuya estructura exportadora dominan las manufacturas y los servicios, es decir, México, Centroamérica y el Caribe. A su vez, las tendencias del precio de los productos básicos serán el factor determinante de la evolución de las exportaciones sudamericanas.

Dada la alta demanda generada por el crecimiento acelerado de los países en desarrollo, incluida la elevada demanda china de metales, los precios tuvieron alzas marcadas. Una vía de transmisión importante fue que los altos precios de la energía, se tradujeron en altos precios en los productos agrícolas que se utilizan para fabricar biocombustibles. 
Cuadro 3. Precios reales de los productos básicos (Deflactados según índice de precios de las manufacturas, $1945-1980=100$ )

\begin{tabular}{|l|l|l|l|l|l|l|}
\hline & $\begin{array}{l}\text { Total no } \\
\text { petroleros }\end{array}$ & $\begin{array}{l}\text { Total } \\
\text { agropecuario }\end{array}$ & $\begin{array}{l}\text { Agropecuarios de } \\
\text { clima tropical }\end{array}$ & $\begin{array}{l}\text { Otros } \\
\text { agropecuarios }\end{array}$ & Metales & Petróleo \\
\hline $1945-70$ & 98.4 & 98.9 & 100.1 & 97.5 & 96.4 & 64.6 \\
$1971-80$ & 104.1 & 103.0 & 99.6 & 106.4 & 109.4 & 192.1 \\
$1981-90$ & 81.1 & 75.5 & 63.1 & 88.2 & 106.4 & 246.3 \\
$1991-97$ & 75.3 & 73.7 & 57.9 & 89.9 & 82.4 & 139.5 \\
$1998-03$ & 69.4 & 67.0 & 50.7 & 83.6 & 80.4 & 193.7 \\
2004 & 75.1 & 69.1 & 52.8 & 85.7 & 102.8 & 290.7 \\
2005 & 80.3 & 72.1 & 59.5 & 84.9 & 118.3 & 410.7 \\
2006 & 96.0 & 76.1 & 63.8 & 88.5 & 187.8 & 487.0 \\
2007 & 102.4 & 80.7 & 69.7 & 91.9 & 202.3 & 518.7 \\
2008 -I & 121.0 & 100.8 & 94.2 & 107.5 & 214.0 & 687.3 \\
2008 -II & 123.3 & 102.1 & 99.1 & 105.0 & 221.5 & 860.7 \\
2008 -III & 112.7 & 94.2 & 88.5 & 100.0 & 198.1 & 810.0 \\
2008 -oct. & 87.9 & 77.3 & 66.6 & 88.2 & 137.0 & 503.4 \\
2008 -nov & 80.3 & 72.6 & 58.3 & 87.0 & 116.3 & 374.2 \\
\hline
\end{tabular}

Fuente: José Antonio Ocampo y María Angela Parra."Los términos de intercambio de los productos básicos en el siglo XX", Revista de la CEPAL, No 79 (LC/G.2200-P), Santiago de Chile, abril de 2003, actualizado por el autor sobre la base de las mismas fuente utilizadas.

Durante el segundo semestre de 2007 y primero de 2008, periodo de fuerte aumento de precios de los productos básicos, la depreciación del dólar y la especulación financiera alimentaron las alzas.

En todo caso, el quiebre de la tendencia de los precios tuvo lugar hacia mediados de 2008 y, por lo tanto, precedió al colapso financiero de septiembre del mismo año.

Sin duda, el colapso de la crisis dañó al comercio internacional, las economías exportadoras de productos básicos, fueron fuertemente afectadas, dado el deterioro de los términos de intercambio.

La recuperación actual del comercio internacional a partir del segundo trimestre del 2009, es liderada por Asia, por el mayor crecimiento de su producción industrial.

c. Corrientes de capital.

Después de la crisis asiática de 1997-98, las economías emergentes, comúnmente conocidas como BRIC, empezaron a acumular reservas extranjeras $y$, consecuentemente, exportando capital al resto del mundo, parte de ese flujo de fondos, se dirigió a cierto número de economías europeas, que recibieron una gran masa de capital.

Conviene subrayar que en los últimos años el componente más dinámico del financiamiento externo muestra dos cambios notables. El primero es el aumento de los activos, sobre todo de las reservas internacionales, pero también de las inversiones directas y de cartera en el exterior, que en todos los casos han superado el crecimiento acelerado del PIB en dólares corrientes de los siete países analizados (que casi se duplico entre 2003 y 2007).

El segundo es el fuerte cambio en la composición de los pasivos, caracterizada esencialmente por la reducción del endeudamiento y la marcada presencia de pasivos de cartera accionarios. 
Estos últimos incluyen las inversiones realizadas en los países de la región por los fondos de inversión internacionales, que también participan en los mercados locales de bonos. Por lo tanto, la contrapartida de este proceso ha sido el auge de los mercados internos, tanto de bonos como accionarios, que de 2001 a 2007 se expandieron 15 puntos porcentuales del PIB.

Las bolsas tuvieron una fuerte caída, pero antes del trastorno de septiembre se encontraban todavía

en un nivel promedio tres veces y media superior al de mediados de 2004.

El colapso de mediados de septiembre de 2008 acentuó drásticamente estas tendencias. Se paralizaron los créditos de todo tipo y se produjo una salida de capitales a través de canales un tanto inesperados: la venta de títulos a lo largo y ancho del mundo para poder satisfacer el retiro de depósitos de los fondos mutuos y de inversión alternativa en Estados Unidos y el desmantelamiento de las operaciones de acarreo (carry trade) que se habían venido realizando desde Japón, uno de cuyos beneficiarios.

\section{d. Inversión extranjera}

En 2008 la inversión extranjera directa en América Latina y el Caribe marcó un nuevo récord histórico, pese a que experimentó una marcada desaceleración respecto del año anterior. Por su parte, la inversión efectuada por empresas latinoamericanas y caribeñas alcanzó el segundo nivel más elevado de la historia.

Las corrientes de IED hacia la región en 2008 superaron un $13 \%$ las del año anterior (CEPAL, 2009). Este resultado es especialmente notable si se compara con la reducción del 25\% que se observó en los flujos de inversión hacia los países desarrollados y del 15\% a nivel mundial. Sin embargo, las cifras agregadas esconden una realidad subregional muy heterogénea. La IED recibida por América del Sur aumentó un $24 \%$ respecto de 2007, impulsada por los altos precios de los productos básicos y el marcado crecimiento económico subregional. Por el contrario, en México y la cuenca del Caribe la inversión extranjera directa disminuyó un $5 \%$ en el mismo período, en gran medida debido a la estrecha relación entre esta zona y la economía estadounidense.

\section{Cuadro 4. América Latina y el Caribe: Inversión Extranjera Directa, 1999-2008 (En millones de dólares)}

\begin{tabular}{|c|c|c|c|c|c|c|}
\hline Subregión o país & 1999-2003* & 2004-2008* & 2007 & 2008 & $\begin{array}{ll}\text { Diferencia } & \text { absoluta } \\
2007-2008 & \\
\end{array}$ & $\begin{array}{l}\text { Diferencia relativa } \\
2007-2008(\text { en } \%)\end{array}$ \\
\hline América del Sur & 43,365 & 57,297 & 72,520 & 89,862 & 17,342 & 24 \\
\hline México & 20,295 & 22,974 & 27,278 & 21,950 & $-5,329$ & -20 \\
\hline Centroamérica & 2,134 & 5,296 & 7,045 & 7,554 & 509 & 7 \\
\hline Caribe & 3,067 & 5,997 & 6,314 & 8,935 & 2,621 & 42 \\
\hline Total & 68,860 & 91,564 & 113,157 & 128,301 & 15,144 & 13.4 \\
\hline
\end{tabular}

Fuente: Comisión Económica para América Latina y el Caribe (CEPAL), La inversión extranjera directa en América Latina y el Caribe, 2008(LC/G.2406-P), Santiago de Chile, 2009.

*Promedio anual.

La segunda fuente de divisas del país luego de las exportaciones de petróleo. En años pasados, esas remesas fueron abundantes y crecientes debido a los millones de latinoamericanos autoexiliados por razones económicas, principalmente en Estados Unidos y Europa. 


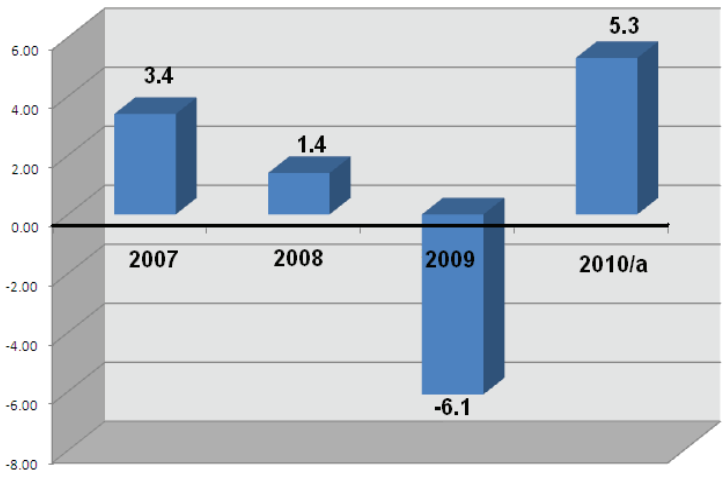

Figura 6. Producto Interno Bruto 20072010 (Variación porcentual real respecto al mismo trimestre del año anterior)

Fuente: Comisión Económica para América Latina y el Caribe (CEPAL), sobre la base de cifras oficiales.

$\mathrm{a} /=$ Cifras preliminares

\section{Efectos de la crisis en México}

Durante los últimos cuatro meses de 2008 se daban los primeros indicios del fenómeno de recesión económica en nuestra nación. En materia de crecimiento según la información proporcionada por el INEGI, durante el 2008 se tuvo una tasa de crecimiento real negativa de $1.4 \%$. Este dato estadístico da la pauta a la identificación del comienzo de la desaceleración

en la economía nacional, en comparación de los indicadores positivos obtenidos en el ejercicio 2006, donde el crecimiento real anual llego al $4.2 \%$ y de igual manera en el $20073.7 \%$.

Como podemos observar esta variable macroeconómica ha venido decreciendo por el choque externo, provocado por la demanda externa.

Respecto a la información que nos muestra la gráfica 7, identificamos que en términos reales la tasa anual de crecimiento económico represento el $-6.1 \%$ para el 2009, hecho que se vio influenciado por la detonación de la recesión del país. Afortunadamente las cifras preliminares del INEGI arrojan números positivos en 2010 de 5.3 y se espera esa tendencia en el 2011. Haciendo una comparación del ejercicio 2008 y 2009 se muestra una caída drástica durante este último periodo, registrando una

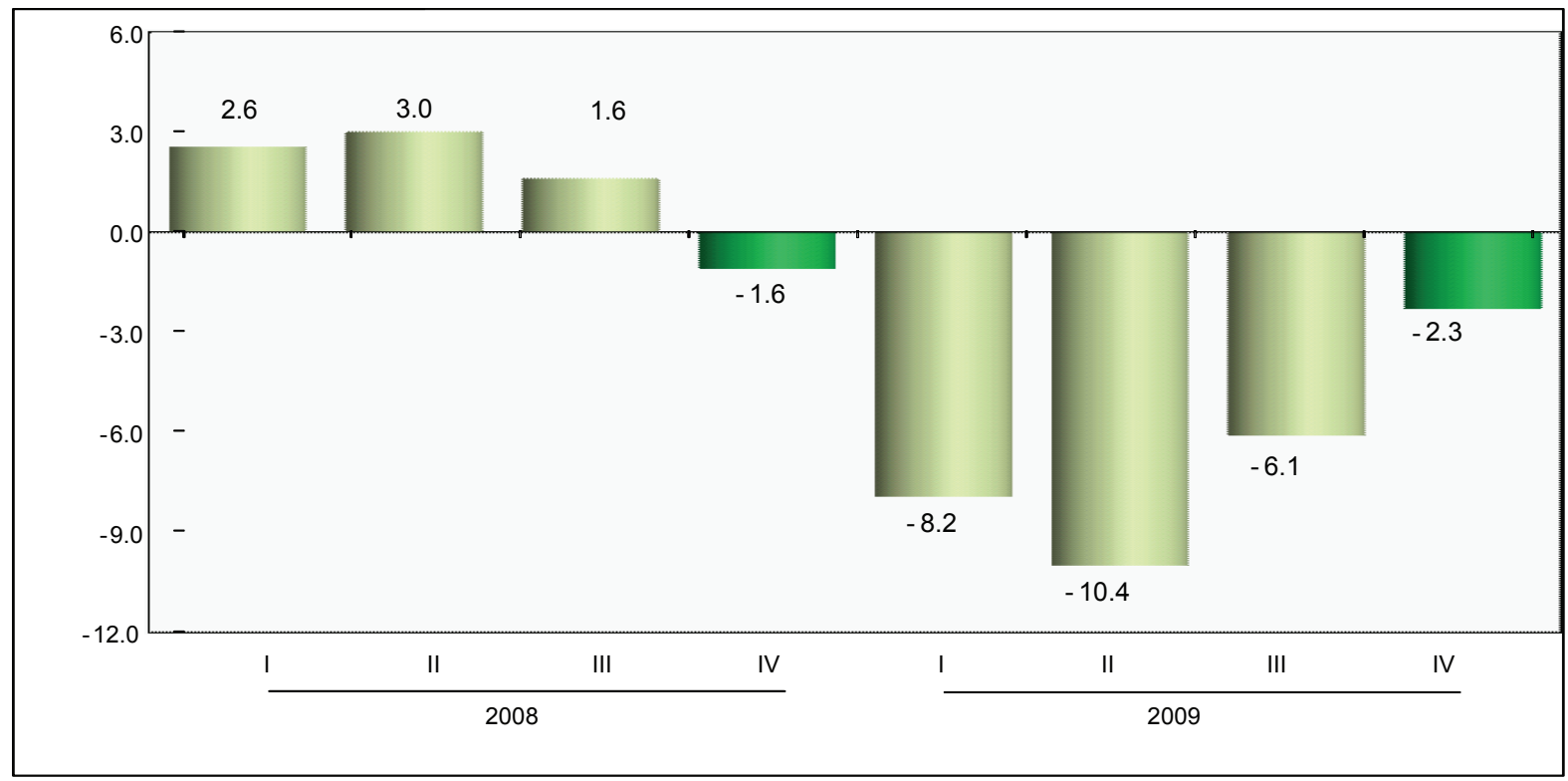

Figura 7. Producto Interno Bruto al cuarto trimestre de 2009 (Variación porcentual real respecto al mismo trimestre del año anterior)

Fuente: INEGI. 


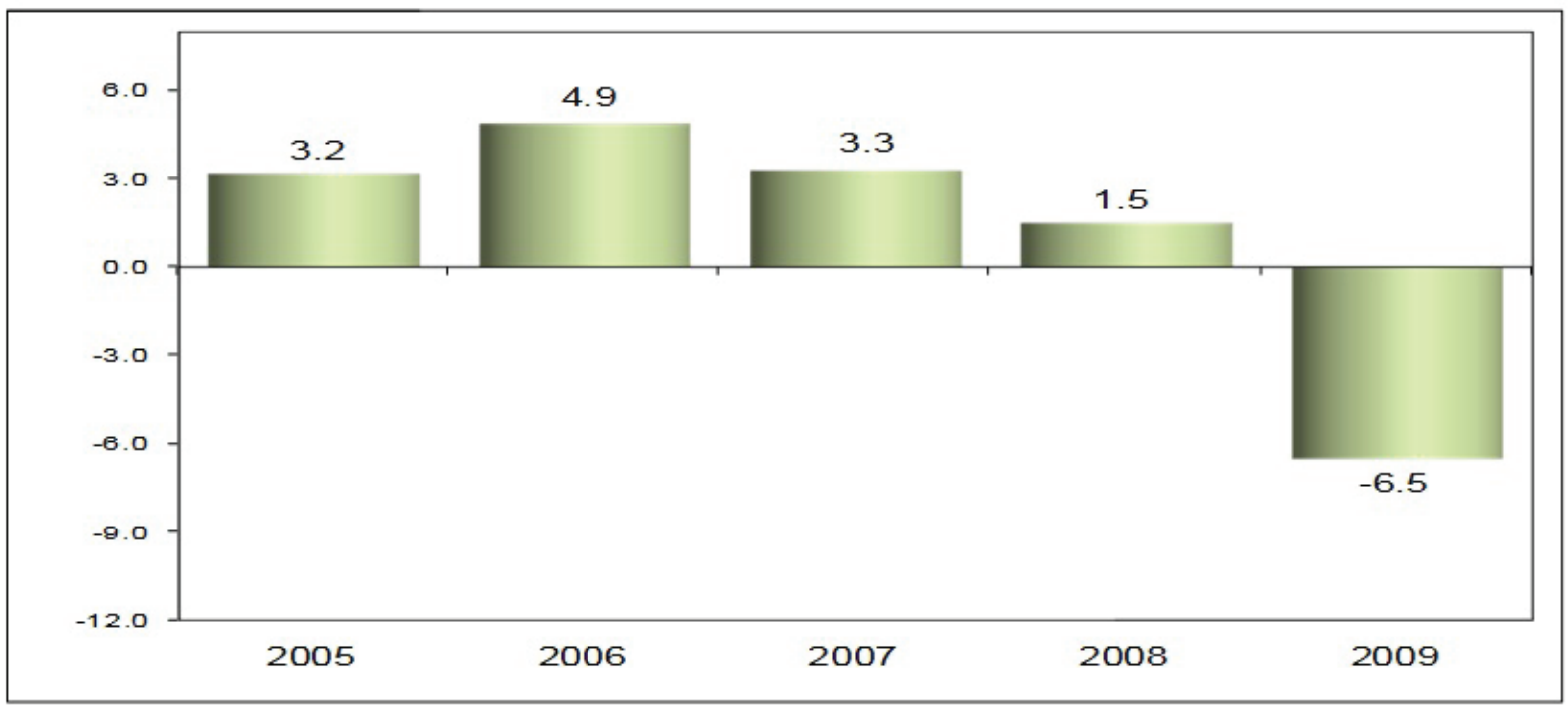

Figura 8. PRODUCTO INTERNO BRUTO ANUAL 2005-2009 (Variación porcentual real respecto al año anterior)

Fuente: INEGI.

variación promedio anual del $-6.1 \%$.

El análisis de este indicador económico, nos muestra que desde el cuarto trimestre de 2008, se provoco una desaceleración que deprimió al sector externo y al mercado interno del país. Por otra parte la contracción del PIB obedece principalmente a la pérdida de la actividad manufacturera y comercial, dado que estas actividades tienen injerencia directa con el mercado del país vecino Norteamericano, aunado a esto, la presencia del brote de la influenza $\mathrm{A}(\mathrm{H} 1 \mathrm{~N} 1)$, trastoco al comercio y al turismo, originando una gran afectación económica en nuestro país.

\section{Comercio Exterior}

Por otra parte, si bien es cierto, la apertura comercial ha incidido en un aumento generalizado de las exportaciones, pero las importaciones registraron una expansión mucho más acelerada. En el 2007, las exportaciones de México ascendieron a

INEGI, Cuentas Nacionales, Sector Externo.

Renglón principal de los ingresos en la balanza comercial de productos petroleros, Datos de INEGI comunicado número 104/10 09 de abril del 2010.

Banco de México. Balanza de pagos. Ingresos por remesas
86.7 millones de dólares, en cambio en el 2008 estas disminuyeron a 75.9 millones de dólares; mientras que las importaciones fueron de 82 mil millones de dólares, arrojando un resultado deficitario en la balanza comercial de 6,100 millones de dólares .

Por un lado las exportaciones de petróleo, en el 2007 las ventas al exterior fueron de 43

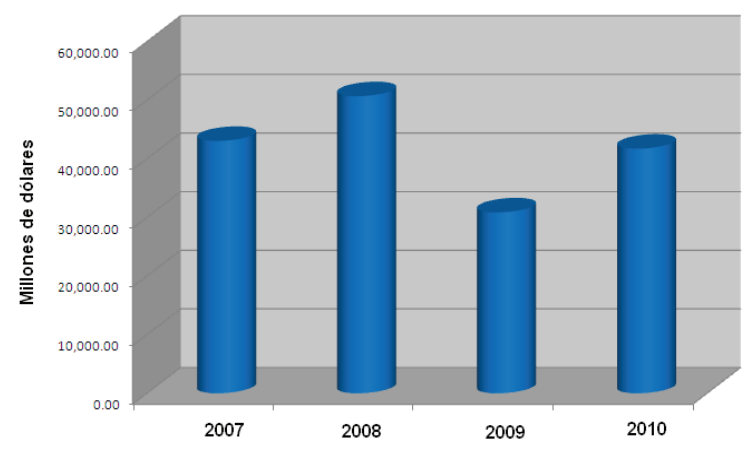

Figura 9. Exportaciones de Petróleo

Fuente: Elaboración propia, basada en datos del INEGI 2011

familiares por Entidades Federativas.

Datos estadísticos del INEGI

Esta devaluación se debe a una carga adicional impuesta a México por el Fondo Monetario Internacional, para contribuir a la recuperación económica de Estados Unidos de Norteamérica. 


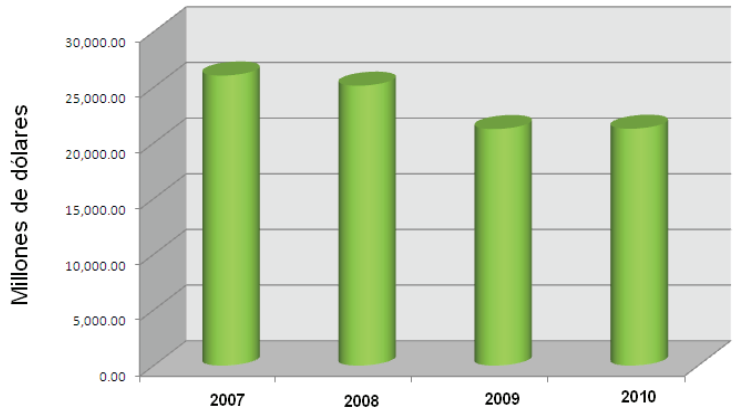

Figura 10. Ingresos por remesas

Fuente: Elaboración propia, basada en datos del INEGI 2011.

mil 18 millones de dólares, mientras que en el 2008 las ventas fueron de 50,639 millones de dólares. El derrumbe de los precios del petróleo ha estado sumamente vinculado con la crisis económica y ha lesionado los ingresos derivados del petróleo, que en el 2009 fueron 30,883 millones de dólares, sin embargo en 2010 se dio un repunte en las ventas al llegar a 41,692 millones de dólares.

Todos estos acontecimientos del colapso del mercado financiero afectaron los ingresos del sector público y con ello las finanzas públicas.

\section{Remesas}

En el rubro de la remesas, renglón muy importante del ingreso de divisas en el sector público manifiesta una tendencia a la baja. En el 2007 se registraron ingresos por 26,049.60 millones de dólares, en el

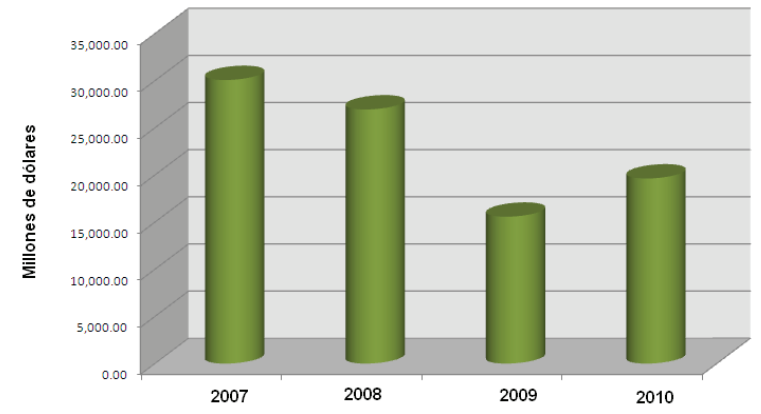

Figura 11. Recursos por inversión extranjera directa

Fuente: Elaboración propia, basada en datos del INEGI 2011
2008 se captaron por este concepto $25,138.6$ millones de dólares, esta propensión a la baja se agudizo en el 2009 (Paz, 2010,pag.100) al percibirse solo 21,244.70 millones de dólares , el 2010 presentó un pobre aumento al quedar en 21,271.20 millones de dólares. La contracción del flujo de este recurso generó una problema en las condiciones de vida de algunas localidades y comunidades del país, en el 2008 este efecto se contrajo 3.6\% frente al 2007 (Moreno-Brid, 2009,pag.77).

Inversión Extranjera

Otro rubro que se vio impactado en los ingresos del sector público ha sido el descenso que acusan los recursos por inversión extranjera. En el 2007, se registro una entrada de 30 mil 069 millones de dólares, pero en el 2008 el total invertido fue de sólo 26 mil 948 millones de dólares , para el año del 2009 se registró un importe de 15 mil 575 millones de dólares, y en el 2010 se obtuvieron 19 mil 626 millones de dólares.

Aunado a esto, se ha manifestado un efecto negativo al devaluarse el peso referente al dólar. Esto lo podemos constatar presentándose en mayo de 2007 un valor de \$10.74 por dólar y para febrero de 2009 la cotización se elevo a $\$ 14.84$, mostrando una de las devaluaciones más elevadas de la década, esta fue del $38 \%$.

Para concluir, la crisis financiera mundial se agudizo en México con la epidemia de la influenza humana AH1N1, dado que dicho fenómeno aceleró el cierre de muchas empresas vinculadas con el sector productivo; con lo que se perdieron miles de empleos. Se dio el derrumbe de las importaciones y exportaciones, aunado al desplome económico de un 8 a un $9 \%$; además los ingresos relacionados con ISR, IVA, IETU y otros impuestos han caído en 


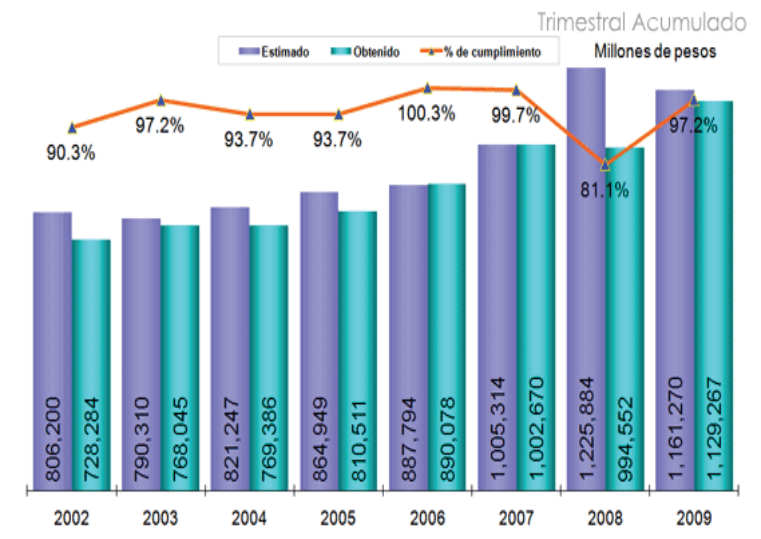

Figura 12. Ingresos tributarios (Enerodiciembre)

Fuente: SHCP y Diario Oficial de la Federación

más de un $15 \%$.

La recaudación de los ingresos tributarios De acuerdo a la Secretaría de Hacienda y Crédito Público (SHCP) durante el año de 2009, la recaudación esperada de los ingresos tributarios presupuestarios fue de $\$ 1$ billón 161 mil 270 millones de pesos, sin embargo, la recaudación real obtenida ascendió a \$ 1 billón 129 mil 267 millones de pesos, esto significa que el porcentaje de cumplimiento fue del $97.2 \%$ y se registro un faltante en la recaudación tributaria del $2.8 \%$. Asimismo podemos destacar el comportamiento que se tuvo de estos ingresos en el ejercicio de 2008, donde lo estimado ascendió a \$1 billón 225 mil 884 millones de pesos, y alcanzándose solamente $\$ 994$ mil 552 millones de pesos, teniendo un cumplimiento del $81.1 \%$, y dejándose de recaudar el $18.9 \%$, esto debido a la crisis internacional.

Comportamiento del precio del petróleo mexicano

La caída de los ingresos petroleros, se debió principalmente al precio de este producto no renovable debido a la desaceleración macroeconómica provocada por la crisis mundial y acentuada en México durante el 2009, tal como se puede observar, el precio de

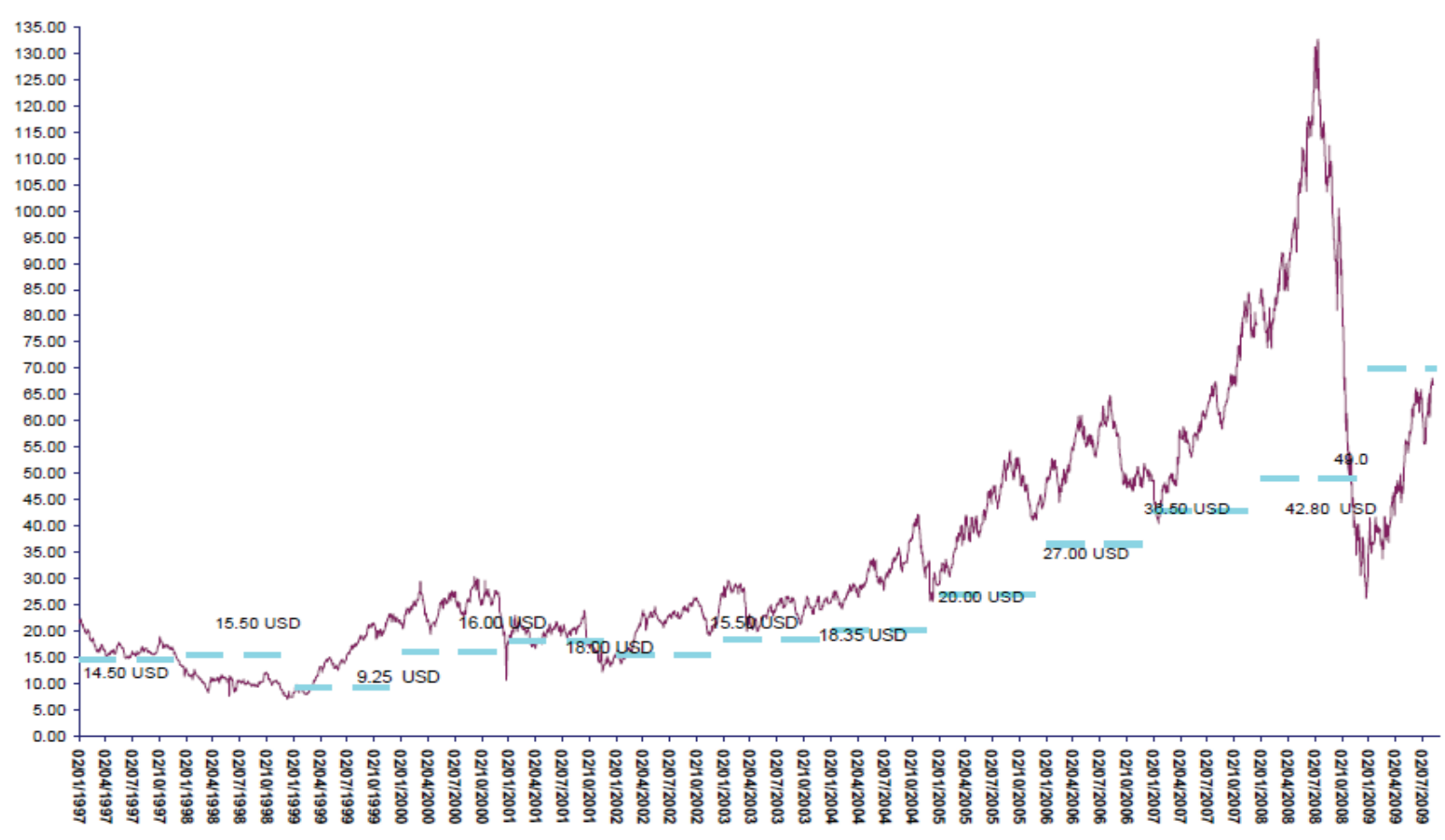

Figura 13. Precio de la Mezcla de Petróleo Crudo de Exportación (1997-2009) (Dólares por barril)

Fuente: Elaborado por el Centro de Estudios de las Finanzas Públicas, con base en datos de PEMEX. 
Cuadro 5. México: diferencia entre el precio del Petróleo Programado y Observado (Dólares por Barril de la mezcla Mexicana de Petróleo Crudo y Exportación)

\begin{tabular}{ccccc}
\hline Año & $\begin{array}{c}\text { Propuesto por el } \\
\text { Ejecutivo }\end{array}$ & $\begin{array}{c}\text { Programado } \\
\text { (Fiscal) } \\
\text { (a) }\end{array}$ & $\begin{array}{c}\text { Observado } \\
\text { (b) }\end{array}$ & $\begin{array}{c}\text { Diferencia } \\
\text { (b)-(a) }\end{array}$ \\
\hline & & & & \\
2000 & 15.50 & 15.00 & 24.64 & 9.64 \\
2001 & 18.00 & 18.00 & 18.57 & 0.57 \\
2002 & 17.00 & 15.50 & 21.53 & 6.03 \\
2003 & 17.00 & 18.35 & 24.74 & 6.39 \\
2004 & 20.00 & 20.00 & 31.02 & 11.02 \\
2005 & 23.00 & 27.00 & 42.73 & 15.73 \\
2006 & 31.50 & 36.50 & 53.05 & 16.55 \\
2007 & 42.50 & 42.80 & 61.72 & 18.92 \\
2008 & 46.61 & 49.00 & 72.67 & 23.67 \\
2009 & 80.30 & 70.00 & 49.57 & -20.43 \\
\hline Tara 2009 se tomó como precio observado el promedio del precio diario de enero a agosto.
\end{tabular}

Fuente: Elaborado por el CEFP de la H. Cámara de Diputados con base en datos de Criterios generales de Política Económica de 2001-2008 y PEMEX.

este producto es altamente volátil afectando de manera importante la recaudación del Gobierno Federal. Los precios por barril durante el ejercicio 2008 alcanzaron los \$132.71 dólares, mientras tanto en el 2009 no se llegó al precio estimado por la Ley de Ingresos de la Federación (\$70 dólares), como se describe en la gráfica y cuadro siguiente.
Según el Centro de Estudios de las Finanzas Públicas de la Cámara de Diputados, contempla que los ingresos por exportaciones de petroleó crudo durante el 2009 ascendieron a \$25 mil 665.6 millones de dólares, representando esto una reducción respecto a $2008 \$ 17$ mil 675.9 millones de dólares o $40.8 \%$. La caída de los ingresos por la exportación de crudo durante el 2009 se debió al efecto combinado de la reducción del precio (que se contrajo a $31.9 \%$ a tasa anual), y de la plataforma de exportación que disminuyo a un $12.7 \%$ (2010, pág. 19). Estos indicadores coinciden con los datos proporcionados por el INEGI, como se observa en el siguiente gráfico.

El contexto anteriormente explicado nos muestra que el Estado Mexicano está fiscalmente débil, aunado a la vulnerabilidad económica provocada por la crisis económica mundial, cuya principal característica es la fuerte contracción de liquidez por la pérdida de riqueza originada por el rompimiento de la burbuja financiera (bienes raíces y derivados), en este sentido, repercutiendo así en las instituciones financieras de los países industrializados.

\section{Ingresos petroleros}

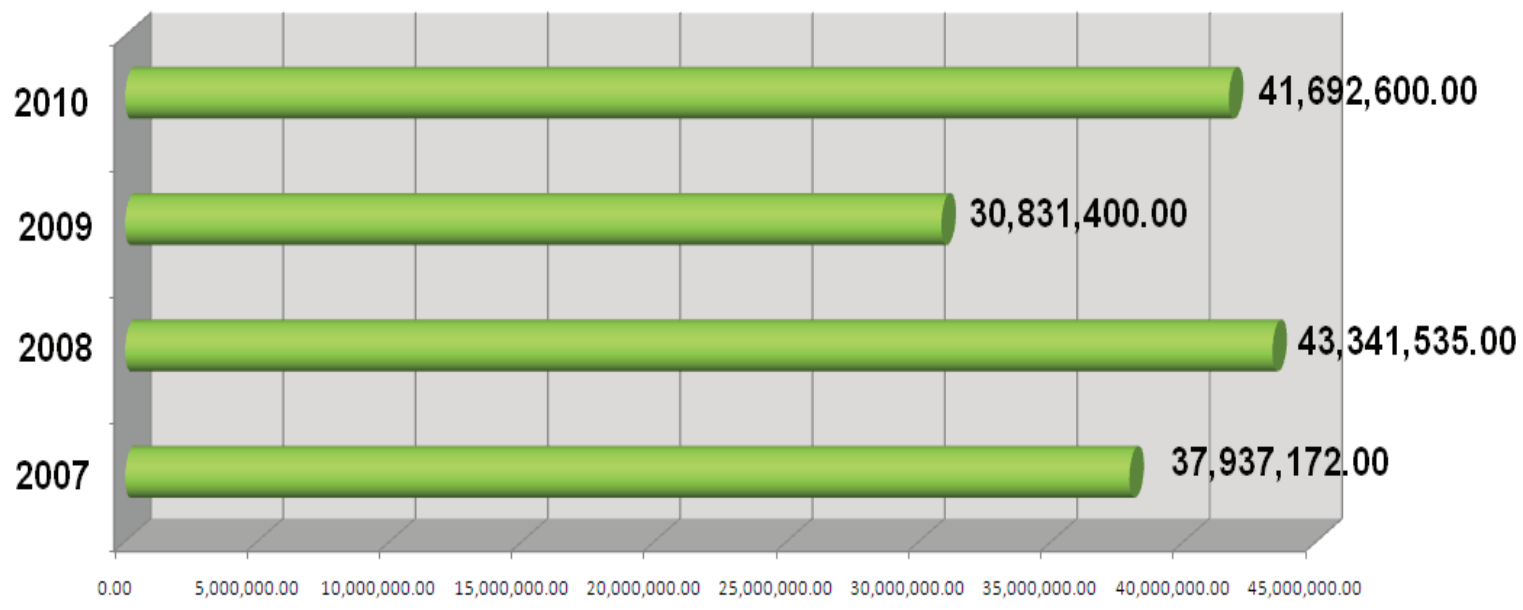

Figura 14. Exportaciones de Petróleo crudo

Fuente: Elaboración propia, basada en datos del INEGI 2011. 


\section{CONCLUSIÓN}

La globalización no es en sí una respuesta lógica de la crisis, en América latina han predominado las ideas negativas, de allí el subdesarrollo que ha sido persistente en la región, si bien es cierto que esta crisis ha afectado a Latinoamérica tan fuerte que no ha podido regresar a los niveles de vida anteriores y pone de manifiesto la vulnerabilidad que tiene, la crisis es tan bien una oportunidad.

En el caso de nuestro país la economía se desaceleró desde principios del 2008, antes del impacto de la crisis internacional, mostrando en el primer cuatrimestre del año una baja en el PIB del 2.6\%, logrando para el segundo cuatrimestre una recuperación del 2.9 del PIB; sin embargo, la economía empezó a contraerse en el tercer cuatrimestre del año, cerrando con -1.6 en el cuarto cuatrimestre. En comparación con el 2007 el PIB decreció un 45.5\%, dado que en el 2007 se tenía un $3.3 \%$ del PIB. Aunado a esto la entrada en vigor del impuesto empresarial a tasa única (IETU) y la reducida inflación interna contribuyeron a acentuar la presión sobre la liquidez para la mayoría de las empresas en la economía, en virtud del crédito restringido por las instituciones financieras. La contracción del mercado externo, a partir del último trimestre de 2008 y durante 2009, frenó drásticamente el único motor del crecimiento que aún tenía dinamismo, llevando a la severa recesión experimentada por la economía mexicana. $\mathrm{La}$ crisis financiera desencadena una onda recesiva que agravará la pobreza, la inseguridad y la exclusión que caracterizan a la realidad del país.

\section{LITERATURA CITADA}

Barack Obama's health reforms. 2009. The Economist , 37-38.

Bernanke, Ben. 2005. The Global Saving Glut and the U.S. Current Account Deficit". Sandridge Lecture, Virginia Association of Economics,Richmond, Virginia.

Bordo, M., Eichengreen, B., Klingebiel, D., \& Martinez-Peria, M. S. 2001. ¿Is the crisis problem growing more severe? Economic Policy, 16 (32), 53-78.

Ferrer, Aldo. 1999. "La Globalización, la crisis financiera y América Latina" Comercio Exterior, Vol. 49, Núm. 6, junio de 1999, México, BANCOMEXT, pp. 527-536

Ferrari, C. 2008. Tiempos de incertidumbre: causas y consecuencias de la crisis mundial. Revista de Economía Institucional , 10 (19), 55-78.

Ffrench-Davis, R. 2009. El impacto de la crisis global en Amércia Latina. Nueva Sociedad (224), 67-85.

Girón, A. 2010. Acciones especulativas y desplomes financieros. Economía Informa (362), 17-22.

Hallivis, M. 2003. Fisco, Federalismo y Globalización en México (Primera ed.). México, D.F.: Tax Editores.

Ibarra, D. 2009. Oteando el futuro. Economía UNAM , 6 (18), 61-74.

Jara, A., \& Tovar, C. 2009. Monetary and financial stability implications of capital flows in Latin America and the Caribbean. Monetary and Economic Department. Basel, 
Switzerland: Bank for International Settlements.

Kindleberger, C. P., \& Aliber, R. 2005. Manias, Panics, and Crashes: A History of Financial Crisis. New York: John Wiley and Sons.

Moreno-Brid, J. 2009. La Economía Mexicana frente a la Crisis Internacional. Revista Nueva Sociedad (220), 60-83.

Morgan, J. 2009. Emerging Markets Outlook and Strategy. Chile.

Ocampo, J. A. 2009. Impactos de la Crisis Finanicera Mundial. Revista CEPAL (97), 9-32.

Paz, F. 2010. La Crisis y sus Efectos en la Economía Mexicana. Revista Economía Informal (362), 93-107.

Reyes, G. 2009. Causas de la Recesión en los Estados Unidos de América (2007-2009). Problemas del Desarrollo Revista Latinoamericana de Economía , 40 (158), 215-233.

Rozenwurcel, G., \& Rodríguez, M. 2009. América Latina 'acoplada' a la crisis como antes al auge ¿Cómo hacer frente a la nueva encrucijada? Centro de Estudios Políticos, Económicos y Sociales. Buenos Aires, Argentina: Fundación friedrich Ebert.

Soros, G. 2008. The New Paradigm for Financial Markets. New York, U.S.A: Public Affairs.

Stiglitz, J. 2009. Como hacer que funcione la globalización (Primera ed.). Madrid, España: Taurus.

Terrones Marco and Cardarelli Roberto. 2005. Global Imbalances: A Saving and Investment Perspective.World Economic Outlook Chapter 2, ,pp. 91-124.
Villagrasa, J. 2003. Globalización: ¿Un Mundo Mejor? México, D.F.: Trillas.

$\mathrm{Xu}$ Jianwei y Yao Yang. 2010. Nuevas formas de división internacional del trabajo, el desarrollo de los mercados financieros y los desequilibrios mundiales, 2010, vol3 pp.3-30.

\section{SITIOS DE INTERNET:}

http://eleconomista.com.mx. (27 de 03 de 2009). Recuperadoel 03 de 01 de 2010 , de http://eleconomista.com.mx/ notas-online/finanzas/2009/03/27/ misterio-detras-activos-toxicos

Osorio, J.A., \&Nicolas, M. 2009. Recuperado el 20 de 01 de 2010, de Banco Central de Reserva de El Salvador: http:// www.bcr.gob.sv/uploaded/content/ category/1109567025.pdf

Tustain, P. (05 de 09 de 2007). www. moneyweek.com. Recuperado el 05 de 01 de 2010, de http://www. moneyweek.com/investmentadvice/how-to-invest/subprimemortgage-collapse-why-bearstearns-is-just-the-start.aspx\&ei=JIy 3S9uVNor2sgPX45npDA\&sa $=X \&$ o $\mathrm{i}=$ translate $\& \mathrm{ct}=$ result\&resnum $=1 \& \mathrm{v}$ $\mathrm{ed}=0 \mathrm{CA} 0 \mathrm{Q} 7 \mathrm{gEw}$

Sergio Enrique-Beltrán Noriega,Candidato a Doctor en Estudios Fiscales, Profesor Investigador de Tiempo Completo de la Facultad de Contaduría y Administración de la Universidad Autónoma de Sinaloa. Correorsergioebn@hotmail.com, Cel. 6673890164.

Rubén Antonio -González Franco, Doctor en Estudios Fiscales, Profesor Investigador de Tiempo Completo de la Facultad de Contaduría y Administración de la Universidad 
EFECTOS DE LA CRISIS DE 2007 EN LAS FINANZAS PÚBLICAS DE MÉXICO

Autónoma de Sinaloa. Correo ruben0304@hotmail.com,_Cel. 6671630614.

Luis Alfredo Ávila-López, Maestro en Economía Mundial, Southwestern University of Finance and Economics. Correo alfredo_ avila20@hotmail.com. 